\title{
Blood-brain barrier dysfunction in ischemic stroke and diabetes: the underlying link, mechanisms and future possible therapeutic targets
}

\author{
Piyawadee Wicha ${ }^{1}$, Srijit Das ${ }^{2}$, Pasuk Mahakkanukrauh ${ }^{1,3}$ \\ ${ }^{1}$ Department of Anatomy, Faculty of Medicine, Chiang Mai University, Chiang Mai, Thailand, ${ }^{2}$ Department of Anatomy, Faculty of Medicine, \\ Universiti Kebangsaan Malaysia Medical Centre, Kuala Lumpur, Malaysia, ${ }^{3}$ Excellence in Osteology Research and Training Center (ORTC), Chiang \\ Mai University, Chiang Mai, Thailand
}

\begin{abstract}
Ischemic stroke caused by occlusion of cerebral artery is responsible for the majority of stroke that increases the morbidity and mortality worldwide. Diabetes mellitus (DM) is a crucial risk factor for ischemic stroke. Prolonged DM causes various microvascular and macrovascular changes, and blood-brain barrier (BBB) permeability that facilitates inflammatory response following stroke. In the acute phase following stroke, BBB disruption has been considered the initial step that induces neurological deficit and functional disabilities. Stroke outcomes are significantly worse among DM. In this article, we review stroke with diabetes-induce $\mathrm{BBB}$ damage, as well as underlying mechanism and possible therapeutic targets for stroke with diabetes.
\end{abstract}

Key words: Blood-brain barrier, Diabetes mellitus, Hyperglycemia, Inflammation, Ischemic stroke

Received November 8, 2020; Revised December 27, 2020; Accepted January 30, 2021

\section{Introduction}

Diabetes mellitus (DM) is a major risk factor for ischemic stroke with its incidence ranging between from 1.8- to nearly 6-fold [1]. Previous study reported that stoke patients with DM show essentially different response to treatment and poor outcome, resulting in increased mortality [2-4]. DM involves microvascular and macrovascular changes, and bloodbrain barrier (BBB) permeability that facilitates inflammatory response following any stroke [5]. Hyperglycemia was

\footnotetext{
Corresponding author:

Pasuk Mahakkanukrauh (D)

Department of Anatomy \& Excellence in Osteology Research and Training Center (ORTC), Chiang Mai University, Chiang Mai 50200, Thailand

E-mail: pasuko34@gmail.com
}

reported to aggravate $\mathrm{BBB}$ damage by affecting both active transport mechanisms and tight junction (TJ) protein [69]. Disruption of BBB may be powerfully associated to other functional abnormalities of the cellular response to ischemia [10]. We reviewed the existing literature on stroke current knowledge of stroke with diabetes-induce BBB damage, as well as its underlying mechanism and possible therapeutic targets for stroke with diabetes.

\section{Structure and Physiological Function of Blood- Brain Barrier}

$\mathrm{BBB}$ is an essential structure for the central nervous system (CNS) that comprises endothelial cells (ECs), basement membrane (BM), end feet of astrocytes, and pericytes (Fig. 1A) $[11,12]$. The contact between all these cells and the functional interactions and signaling from a dynamic functional

\section{Copyright ( 92021 . Anatomy \& Cell Biology}

This is an Open Access article distributed under the terms of the Creative Commons Attribution Non-Commercial License (http://creativecommons.org/licenses/by-nc/4.0/) which permits unrestricted non-commercial use, distribution, and reproduction in any medium, provided the original work is properly cited. 
unit, which is known as the neurovascular unit (NVU).

\section{Cells of blood-brain barrier}

The ECs are a single layer of squamous shape cells that line the interior of brain capillaries. The ECs of brain have unique properties that exceedingly limit the paracellular influx of solution. The ECs were separated from pericytes and end feet of astrocytes by BM that are composed of fibronectin, collagen type IV, nidogen, laminin, heparin sulfate proteoglycans, and other glycoproteins [13]. BM equips an anchor for many signaling processes at the vessel and also equips barrier for molecules and cell to cross before accessing the brain parenchyma. BM damage by matrix metalloproteinase (MMP) is the considerable element of $\mathrm{BBB}$ disruption and neutrophil infiltration. ECs of brain are held together by TJ proteins. TJ proteins are composed of the transmembrane proteins claudins, occludins, and junction adhesion molecules, and the cytoplasmic proteins zona occludens that provide a high-resistance physical barrier to ions and molecules [14]. Another characteristic of central nervous system ECs is the low expression of leukocyte adhesion molecule [15]. Therefore, immune cell never cross an unstimulated BBB to protect the healthy CNS [16].

Astrocytes are abundant cell type in the brain parenchyma are associated with BBB by endfeet protrusions ensheathing the capillaries. They play important role in recycling of neurotransmitter and ions, synapse formation, regulation of extracellular potassium levels, nutrition of neuron, and control of inflammatory responses in CNS [17]. Pericytes are cells that wrap around the vascular ECs in an approximate 3:1 pericyte-to-EC ratio. Previous study reported that, pericytes are important for cerebral blood flow and BBB integrity $[18,19]$.

\section{Tight junction}

TJ proteins have several functions in the ECs. ECs in CNS are held together by TJ proteins, which provide a highresistance epithelial barrier [20]. Claudins occludins and members of junctional adhesion molecules (JAMs) are transmembrane molecule that are essential for the paracellular barrier formation (Fig. 1B). Claudins are a class of more than 25 different family members and these proteins are of primary importance for optimal establishment of TJ proteins. A previous study reported that a size-selective leak of BBB was found in claudin-5-deficient mice [21]. Claudin-5 has been shown to be largely identified by ECs in CNS. Moreover, cldn 12 and cldn 3 are other claudins that have been expressed at the BBB $[19,21,22]$. Occludin was found localizing to epithelial cells and It is highly enriched CNS ECs. A previous study found that occludin may not be important for the resistance of barrier, as described by occludin knockout mice which showed a normal function of BBB and high-resistance barrier [23]. JAMs are members of an immunoglobulin superfamily. It is localized in many tissue including leukocytes, epithelial and ECs. JAM4 has been found in the BBB [19]. However, a previous study reported that JAMs are not necessary for TJ proteins component. The transmembrane adhesion complexes are linked to the cytoskeleton through a
A

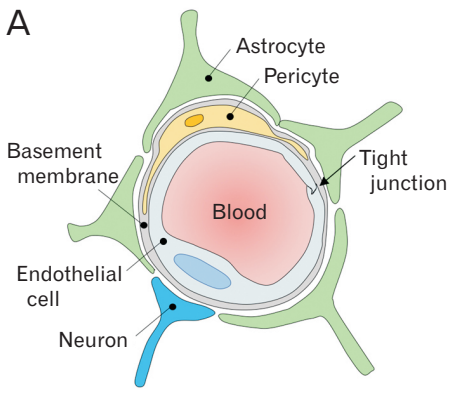

C

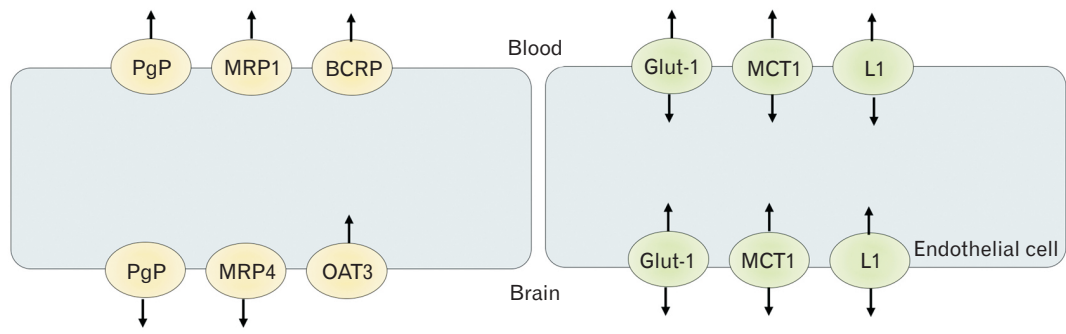

B Blood

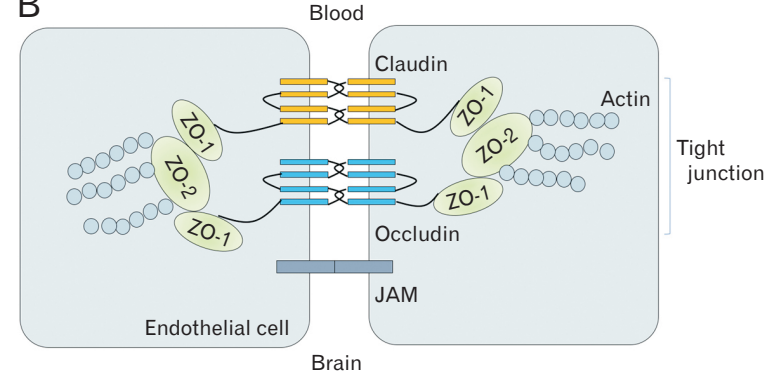

Fig. 1. Structure and functionality of the BBB. (A) Structure of BBB is composed of ECs, BM, astrocyte end feet and pericytes. (B) Tight junctions on ECs (C) Transporter of BBB for molecular traffic across the BBB. BBB, bloodbrain barrier; $\mathrm{BM}$, basement membrane; ECs, endothelial cells; Glut-1, glucose transporter; ZO-1, zona occuldens-1. 
series of cytoplasmic adaptors such as zona occuldens-1 (ZO1), ZO-2, Cingulin, Jacop, membrane-associated quanylate kinases, and membrane palmitoylated proteins [24].

\section{Transporter}

There are two main types of membrane transporter proteins at the level of the brain microvascular endothelium including efflux transporters and nutrient transporters (Fig. 1C) [20]. Efflux transporters are implicated in drug transporter at BBB, including P-glycoprotein (P-gp), breast cancer resistant protein and the multidrug resistance-associated proteins. These transporters are located to the lumenal surface of ECs and transport compounds across the BBB into the blood circulation. P-gp is the main efflux transporter that involved in transport substrates into blood [25]. P-gp deficient could be developed various neurodegenerative disorders, such as Alzheimer's disease, Parkinson's disease and stroke [26].

ECs in CNS express a many nutrient transporters that stimulate the movement of specific nutrients across the BBB into the brain parenchyma. There are many solute carrier classes of facilitated transporters, including slc2al (glucose), slc7a1 (cationic amino acids), slc7a5 (neutral amino acids, LDOPA), and slc16al (lactate, pyruvate). Dysfunction of glucose transporter (glut-1) causes an epileptic syndrome. Glut1 carries glucose across the $\mathrm{BBB}$, while glut- 3 is the main neuronal glucose transporter [27]. Insulin-sensitive glut-4 also plays important role in carrying glucose to brain [27].

\section{Diabetes Mellitus and Blood-Brain Barrier Dysfunction}

DM is a condition where there is increase blood sugar or glucose levels that is a major cause of heart attack, kidney failure and stroke. There are two main types of diabetes: insulin-dependent (type $1 \mathrm{DM}, \mathrm{T} 1 \mathrm{DM}$ ) and insulin-independent (type $2 \mathrm{DM}, \mathrm{T} 2 \mathrm{DM}$ ). T1DM is a disease in which the pancreas loss of beta cells that fails to provide enough insulin, while T2DM is characterized by insulin resistance, a condition in which cells are not respond to utilize insulin. A chronic state of low-grade inflammation, endothelial dysfunction, dyslipidaemia, insulin resistance, and hyperglycemia or high blood sugar, is a characteristic symptom of diabetes that can lead to serious complications at the microvascular level, described by experiment both in vitro and in vivo study [28]. Changes in plasma glucose levels (hyperglycemia or hypoglycemia) have been related with BBB transporter functions, and oxidative stress in the CNS capillaries [29].

Gluts at the BBB sustains energy demands of CNS. Glut1 and glut- 3 are major transporters at BBB. Previous studies reported that concentration of brain glucose increases in streptozotocin (STZ) induced-diabetics rat as measured by NMR spectroscopy [30]. Moreover, hyperglycemic animals were found to have down-regulation of $\mathrm{BBB}$ glucose transporter. Prolonged hyperglycemia in STZ-induced diabetic rats showed down-regulated glut-1 and glut-3 expression

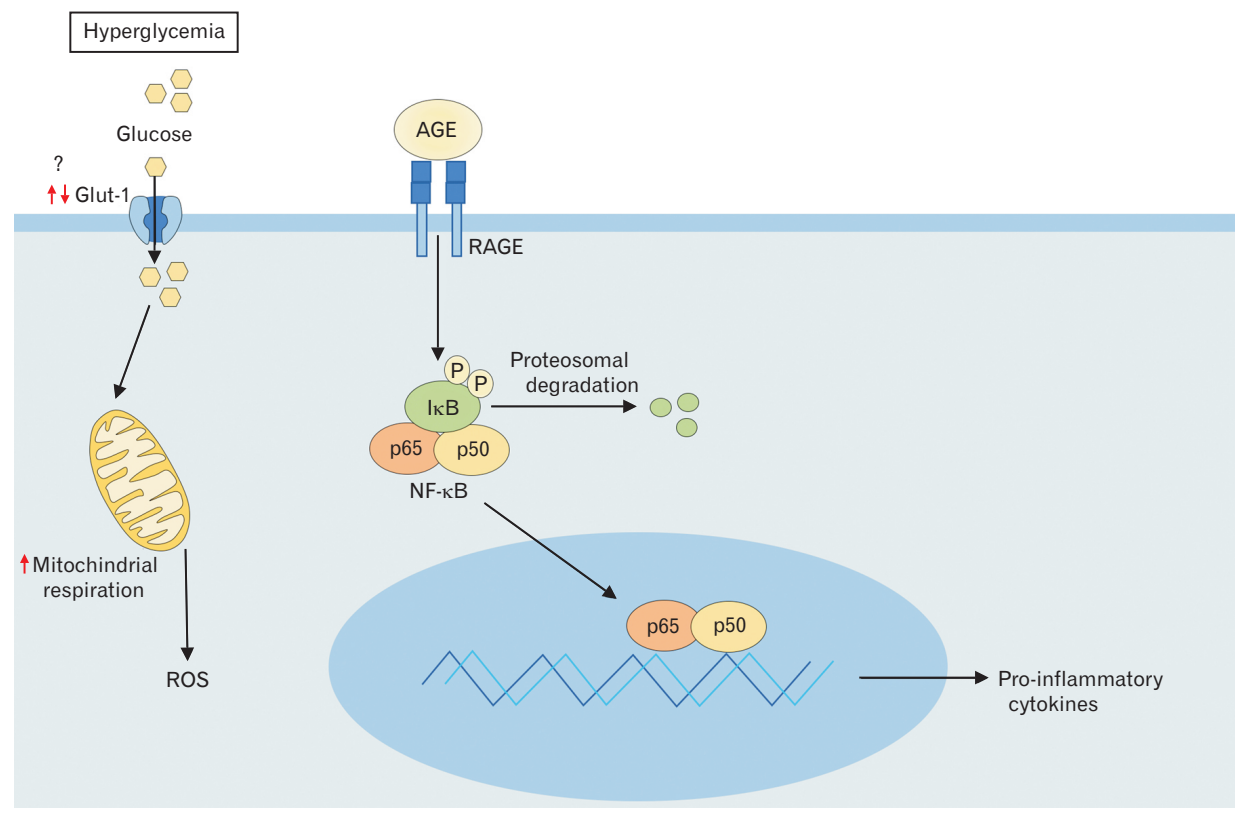

Fig. 2. Pathological mechanism of inflammation induced by hyperglycemia. Glut-1, glucose transporter; NF- $\kappa \mathrm{B}$, nuclear factor-kappa B; ROS, reactive oxygen species. 
[29]. On the other hand, other studies showed that there was no significantly change in the BBB glucose transporters in DM. Previous study reported that there were no significant changes in the expression of glut-land glucose uptake in STZ-induced diabetic rats [31]. In human experiment, acute hyperglycemia did not significantly change in regional glucose metabolism as measured by high-field magnetic resonance spectroscopy. Moreover, a previous study reported that plasma glucose levels did not change in dependence of hippocampus in diabetic animals.

The microvascular injury in DM caused by the overexpression of mitochondrial superoxide overproduction in the ECs. The overproduction of superoxide can activate the formation of advanced glycation end product (AGE) and protein kinase $\mathrm{C}(\mathrm{PKC})$ signaling. $\mathrm{PKC}$ induces $\mathrm{BBB}$ damage through TJ proteins disruption, ZO-1 phosphorylation, and overproduction of vascular endothelial growth factor expression. Upregulation and activation of the receptor for advanced glycation end products (RAGE) induce oxidative stress and leads to activation of nuclear factor-kappa $B$ (NF- $\kappa \mathrm{B})$ pathway [32]. NFКB pathway activated in vascular cell that subsequently increase leukocyte infiltration and transcription of proinflammatory cytokines including tumor necrosis factor- $\alpha$ (TNF- $\alpha$ ), interleukin-6 (IL-6), and interleukin-1 $\beta$ (IL-1 $\beta$ ) (Fig. 2). A previous study reported that hyperglycemia can induce reactive oxygen species (ROS) production and increase proinflammatory cytokines and chemokines in many cells $[33,34]$. Moreover, in hyperglycemic animals, diabetic animals and diabetic patients showed the expression of adhesion molecule on ECs [34]. Furthermore, it has been reported that ROS can activate MMPs including MMP-1, MMP-2, and MMP-9 while attenuating TIMP metallopeptidase inhibitor-1 (TIMP-1), known as a tissue inhibitor of MMPs. Particularly, MMP-9 degrade the extracellular matrix (ECM) constituents of the $\mathrm{BM}$ and $\mathrm{TJ}$ proteins including occludin, claudin-5, and ZO-1. These inflammatory events induce $\mathrm{BBB}$ disruption that lead to the extravasation of leukocyte into brain. Leukocyte infiltration are related to the severity of $\mathrm{BBB}$ damage.

\section{The Connection Between Ischemic Stroke and Diabetics}

Globally, Stroke is the second-most common cause of mortality worldwide and is a major cause of long-term disability globally [35]. World Health Organization describes stroke as a focal (or at times global) neurological impairment of sudden onset and lasting more than 24 hours (or leading to death) and of presumed vascular origin. The risk factors for stroke are age, race, sex, hypertension, cardiac disease, smoking, alcohol use, obesity and DM. It may be mentioned that DM is the major cause of mortality in patients with stroke [36]. The patients with DM are associated with an increased risk of ischemic stroke. Moreover, hemorrhagic strokes are relatively less common in diabetes DM than in nondiabetic individuals.

Ischemic stroke causes a decrease in the blood flow sufficient to alter normal cellular function. Oxygen and glucose deprivation during cerebral ischemia triggers a cascade of events that includes the disruption of membrane potential due to the reduction in ATP production and mitochondrial membrane damage, which leads to a release of excitatory neurotransmitters such as glutamate. Binding of glutamate to its receptors resulting in increases calcium influx leading to mitochondrial function impairment via activation of protein kinase, phospholipase, protease, nitric oxide synthase and release of free radicals. ROS may result in tissue injury through several mechanisms. As they are potent oxidizing and reducing agents, ROS directly damage cellular membranes through lipid peroxidation. The excessive production of ROS can induce apoptosis. In addition, ROS also increase leukocyte adhesion molecule and cytokine gene expression by activating the NF- $\kappa \mathrm{B}$ signaling the pathway that important role in the inflammatory process and frequently associated with BBB damage and followed by brain edema $[37,38]$.

Inflammatory responses were observed in the brain following stroke. ROS can activate downstream signaling pathways, NF- $\kappa \mathrm{B}$ signaling pathway. NF- $\kappa \mathrm{B}$ composes of a family of transcription factor that play a role in inflammation.NF- $\kappa \mathrm{B}$ activation causes a phosphorylation-induced the degradation of inhibitory $\kappa \mathrm{B} \alpha$ and the nuclear translocation of p65 subunit, causing the infiltration of peripheral inflammatory cells, activation of microglia, and overproduction of inflammatory mediators, such as cytokines, chemokines, and MMPs. Overexpression of iNOS and COX-2 have appeared as important determinants of ischemic stroke that lead to the progression of brain injury. Increasing amount of ROS after I/R activates astrocytes and microglia to produce proinflammatory cytokines such as TNF- $\alpha$, IL- 6 , and IL-1 $\beta$. Most of these cytokines can induce the production of adhesion molecules such as inter selectins, immunoglobulin superfamily (ICAM-1, VCAM-1) and integrins. Adhesion mol- 


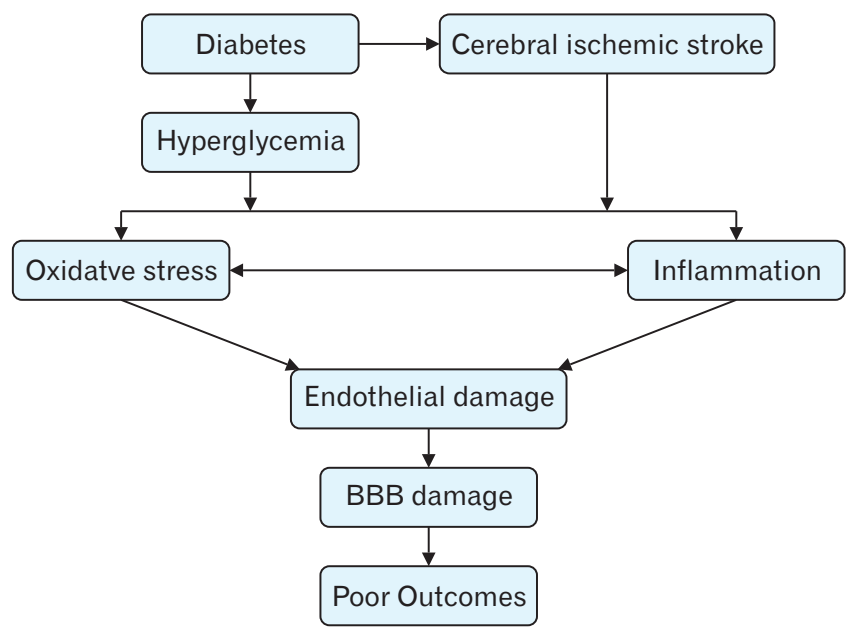

Fig. 3. Neuroinflammatory mechanism involved in aggravating BBB damage in stoke with diabetic. BBB, blood-brain barrier.

ecules on activated endothelial in turn lead to the adhesion of circulating leukocytes causing infiltration of immune cells into the brain parenchyma. The inflammatory cells release a variety of cytotoxic molecules, such as pro-inflammatory cytokines, especially production of ROS and activation of MMPs. Particularly, MMP-9 degrade the ECM constituents of the BM and TJ proteins including occludin, claudin-5, and ZO-1 $[39,40]$. These inflammatory events induce BBB disruption that lead to the extravasation of serum constituents as serum proteins and serum immunoglobulin $\mathrm{G}(\mathrm{IgG})$ into brain. IgG entry and extravasation are related to the severity of BBB damage (Fig. 3).

Hyperglycemia is serious problem in DM. It has been reported that prolonged hyperglycemia causes a progressive functional impairment of neuronal in brain. Ischemic stroke is typical and are typical CNS complications associated with DM due to the vascular supply impairment. A previous study showed that patients with DM are have a higher risk of experiencing stroke than healthy people. Moreover, $50 \%$ of stroke patients were diagnosed with high blood sugar or hyperglycemia $[2,41]$. Hyperglycemia is strongly related to high mortality and morbidity level in ischemic stroke patients with by increased ROS production damaging BBB. A previous study reported that AGE-RAGE system activated by hyperglycemia causes important role in increasing oxidative stress and inflammatory response in brain [42]. In animal study, ROS production and products of anaerobic metabolism increase permeability of the $\mathrm{BBB}$, worsen brain edema and aggravate brain damage [43]. Altered glycemic conditions in patients with diabetic are prodromal to $\mathrm{BBB}$ damage. The increased incidence of hemorrhagic transformation in patients with post-stroke hyperglycemia also points to possible disruption of BBB integrity [44]. Therefore, prolonged high blood glucose following stroke is a factor for BBB disruption that leads to worse functional outcome, hence treatment strategies to normalize blood sugar levels after stroke are essential.

\section{The Possible Therapeutic Targets}

We reviewed the most recent finding that associated to the pathophysiology of high blood glucose in ischemic stroke. The therapeutic targets were also discussed in this present review as shown in Table $1[46,52,60,63,64,66-73$, $76,80,81,83,88-90,92-96]$.

\section{Angiotensin receptor blocker}

Angiotensin receptor blocker (ARB) is widely used by patients with hypertension that bind to and inhibit the angiotensin II receptor type 1 [45]. Previous study reported that $\mathrm{ARB}$ can improve ECs functions and remodel left ventricular hypertrophy [46]. Moreover, ARB also decrease cardiovascular mortality, myocardial infarction, sudden cardiac arrest, and stroke [46]. Animal studies have also showed protective effects of ARB against organ damage in animals with DM, or hypertension with or without metabolic syndrome. The effects of ARB appear to be linked to improved insulin sensitivity and decreased arterial stiffness, sympathetic activity, and inflammatory response [47-49]. Moreover, ARB can elicit anti-atherosclerotic effects through activating of peroxisome proliferator-activated receptor gamma (PPAR $\gamma)$ [50]. Therefore, ARB is accordingly suggested as the first line antihypertensive drugs in patients with cardiovascular diseases [51]. Previous study suggested that the use of ARB before onset may be useful for long-term functional outcome following ischemic stroke in diabetic patients [52]. However, the mechanism of ARB on hyperglycemia with ischemic stroke have not been clarified.

\section{Antihyperglycemic}

Hyperglycemia on admission is associated with increased mortality and poor functional outcomes in patients with stroke [53, 54]. Hyperglycemia might occur in response to stress as a consequence of severe stroke [2]. Although improved glycemic control has been shown to reduce the risk of microvascular complications of T2DM, its benefit for macrovascular risk reduction has been unclear [55-59]. There 


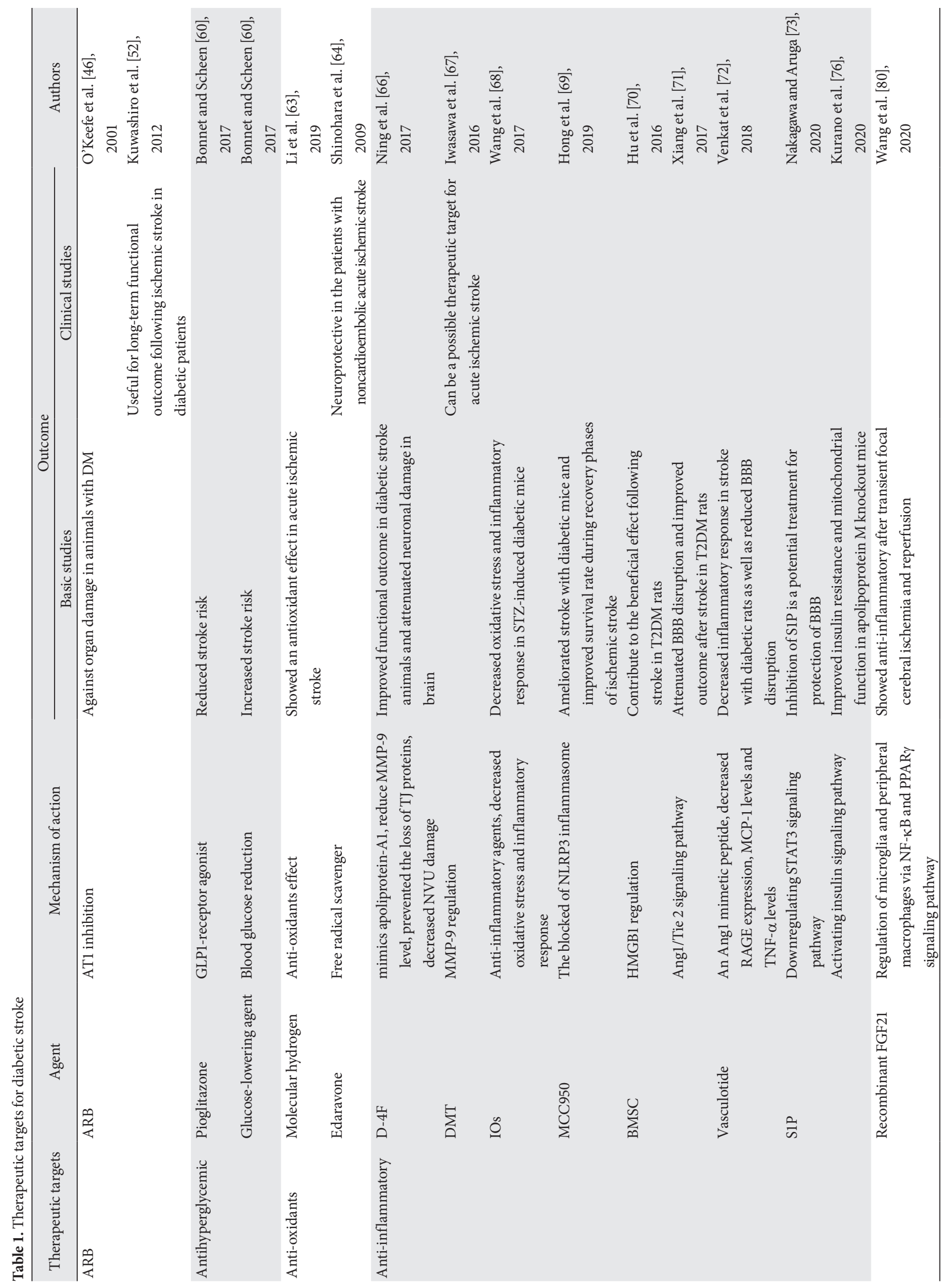




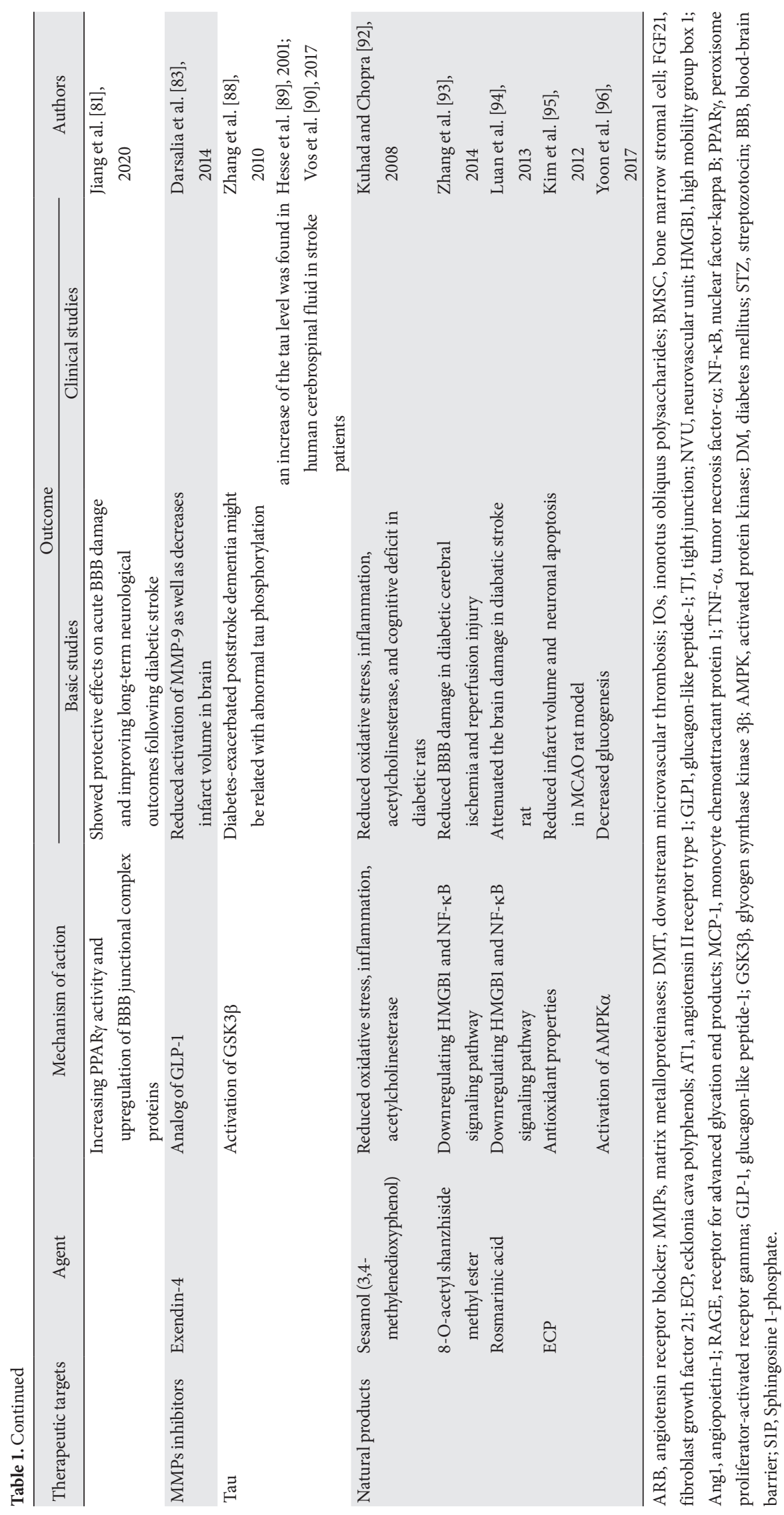


is still uncertainty regarding the cardiovascular outcome benefits or neuroprotective effect of glucose-lowering treatment after stroke. Previous study reported that pioglitazone, glucagon-like peptide-1 (GLP-1) receptor agonists, conferring possible reduction stroke risk, while other classes showing a neutral impact (DPP-4 inhibitors, insulin) and some glucose-lowering agents being associated with an increased risk of stroke [60]. Currently, the accumulated evidence suggests that metformin, pioglitazone and semaglutide possible protect against cerebral ischemic stroke. These agents do not represent only a way of regulating glucose and but also offer the opportunity to reduce stroke risk. Surely, new data from ongoing and future studies will provide additional information to choose effective treatment for decreasing stroke risk in T2DM patients [61].

\section{Anti-oxidants}

Hyperglycemia and AGE can induce ROS production that lead to neuronal cell death. Anti-oxidant strategies are believed to be a promising treatment for ischemic stroke [62]. A previous study reported that oxidative stroke is more pronounced in diabetic acute cerebral ischemic stroke patient than in nondiabetic acute cerebral ischemic stroke patient. Additionally, counterbalancing antioxidant capacity are more pronounced in diabetic acute stroke patients. A blocked of ROS is suggested to terminate apoptotic process and may reduce neurological deficit. Previous study showed the neuroprotection of molecular hydrogen, as an antioxidant, in acute ischemic stroke [63]. Moreover, Edaravone, a free radical scavenger and agent used for treatment of amyotrophic lateral sclerosis, was found to be neuroprotective in the patients with noncardioembolic acute ischemic stroke [64]. However, using of antioxidants did not fully translate successfully in to the clinical application despite the role of ROS in mediating brain damage. The lack of clinical evidence on the benefit effects of anti-oxidant in stroke with diabetes need to be ascertained in detail in further research.

\section{Anti-inflammatory}

Hyperglycemia causes oxidative stress, which further results in inflammation following BBB damage. Agents Bradykinin 1 receptor (B1R) is an important role in persistent pain and inflammation. Activation of B1R was found to be a cause of hemorrhage in stoke with diabetes animals [65]. B1R activation increased MMP-9 overexpression causing cerebral hemorrhage. B1R blocking lead to the reduction of NVU barrier damage causing less cerebral hemorrhage.

Moreover, D-4F, a peptide that mimics apoliprotein-A1, was found to improve functional outcome in diabetic stroke animals through reduction of inflammatory process. Furthermore, D-4F also reduced MMP-9 level, prevented the loss of TJ proteins, decreased NVU damage, and attenuated neuronal damage in brain. Additionally, treatment of stroke with diabetic rats decrease BBB disruption and white matter damage thereby improving functional outcome [66]. These provide concrete evidence that $\mathrm{D}-4 \mathrm{~F}$ is a promising neuroprotectant for stroke with diabetes.

Downstream microvascular thrombosis (DMT) is known to be a contributing factor for incomplete reperfusion in acute ischemic stroke that induced by ischemia and further aggravated by high blood sugar. A common link of the DMT mediators is MMP-9 activation. Previous study reported that DMT mediators can be a possible therapeutic target for acute ischemic stroke where high blood glucose increases cerebral ischemia and reperfusion injury [67].

Study showed that inonotus obliquus polysaccharides (IOs) and metformin, used as anti-inflammatory agents, decreased oxidative stress and inflammatory response in STZinduced diabetic mice [68]. Moreover, IOs can be a promising novel agent for treatment related to neuronal protection.

NLRP3 inflammasome is significantly associated to diabetics and stroke. A previous study reported that the blocked of NLRP3 by MCC 950 ameliorated stroke with diabetic mice and improved survival rate during recovery phases of ischemic stroke [69].

Other studies have demonstrated bone marrow stromal cell (BMSC) treatment of stroke reduces BBB disruption and improves functional outcome after stroke in T2DM rats. Regulation of high mobility group box 1 (HMGB1) and RAGE expression by BMSC treatment may contribute to the beneficial effect following stroke in T2DM rats [70]. Furthermore, BMSC conditioned medium can attenuates BBB disruption and improve outcome after stroke in T2DM rats through angiopoietin-1 (Ang1)/Tie 2 signaling pathway [71].

Moreover, previous study revealed that diabetes related with reduction of Ang1 that has powerful vascular protective effects. Vasculotide, an Ang1 mimetic peptide, that has antiinflammatory effects. Vasculotide decreased RAGE expression, MCP-1 levels and TNF- $\alpha$ levels in stroke with diabetic rats as well as reduced BBB disruption. It is suggested that vasculotide-induce neuroprotective effects in stroke with diabetes [72]. 
Sphingosine 1-phosphate (S1P) is a main bioactive lipid mediator in the immune system, infiltration of the peripheral blood cells into the CNS, endothelial barrier integrity, and inflammatory responses [73-75]. During disease states such as cardiovascular disease and diabetic, S1P elicits both harmful and beneficial effects depending on the receptor type that is activated. Previous study indicated that inhibition of S1P is a potential treatment for protection of BBB in both in vitro and in vivo model after ischemia through downregulating STAT3 pathway [73]. Moreover, Apolipoprotein M/S1P also has protective effect against insulin resistance through activating insulin signaling and improving the mitochondrial functions in apolipoprotein M knockout mice [76].

Human fibroblast growth factor 21 (FGF21) is an endocrine member of fibroblast growth factor family that plays important role in glucose metabolism, lipid metabolism and energy balance [77-79]. Previous study demonstrated that the anti-inflammatory effect of recombinant FGF21 on transient focal cerebral ischemia and reperfusion occurs through regulation of microglia and peripheral macrophages via NF$\kappa \mathrm{B}$ and PPAR $\gamma$ signaling pathway [80]. Moreover, recombinant FGF21 has been showed protective effects on acute BBB damage following diabetic stroke through increasing PPAR $\gamma$ activity and upregulation of BBB junctional complex proteins [81]. In addition, it has beneficial effect for improving long-term neurological outcomes in T2DM [81]. Therefore, recombinant FGF21 might be a potent candidate of the disease-modifying strategy for treating diabetic stroke.

Anti-inflammation is considered a prime target for development of new stroke with diabetes therapies. However, these facts need to be studied in detail in future.

\section{Matrix metalloproteinases inhibitors}

MMP-9 are proteolytic enzymes that play an important role in neuroinflammatory disorder through $\mathrm{BBB}$ damage. Previous study reported that upregulation of MMP-9 expression in diabetic patient has an important relation with the level of blood glucose. Zhong and coworkers [82] investigated between MMP-9 levels and the prognosis of 300 acute ischemic stroke patients. They found that increased risk of disability and mortality were related with high serum MMP9 levels. Therefore, blockage of MMP-9 may act potential treatment agents for stroke with diabetes. Exendin-4, a longacting analog of the hormone GLP-1, was investigated the effect on attenuating glucose levels in hyperglycemic mice and cerebral ischemic stroke [83]. The data showed that GLP-1 reduces activation of MMP-9 as well as decreases infarct volume in brain. Moreover, a previous study revealed that GLP1 exhibits antioxidant effect that attenuates inflammatory response in T1DM and prevents the ECs dysfunction. It was concluded that anti-MMP-9 is a potential therapy for stroke with diabetic, but clinical trials in patients are limited.

\section{Tau protein}

Tau protein mainly expressed in adult human brain that plays a crucial role both in neurogenesis and stoke [84]. Tau hyperphosphorylation was found following cerebral ischemic damage in rat brain and hypoxia-dependent in vascular dysfunction model [85-87]. Previous study reported that diabetes-exacerbated poststroke dementia might be related with abnormal tau phosphorylation through activation of glycogen synthase kinase $3 \beta$ (GSK3 $\beta$ ) in hippocampus [88]. Moreover, the change in pattern of phosphorylation of tau associated with BBB dysfunction in brain ischemia. In clinical studies, an increase of the tau level was found in human cerebrospinal fluid in stroke patients [89,90]. Nowadays, researcher have found several methods to regulate the tau levels such as methylene blue, AMK-activated protein kinase (AMPK)-related kinase Nuak1, ERK inhibitor, GSK3 $\beta$ [84].

\section{Naturals products}

Several studies investigated the natural compounds in diabetic rats with stroke. A previous study reported that curcumin reduced neuronal apoptosis in brain and cerebral infarct volume, by upregulating glut1 and glut3. These results suggested that curcumin may protect DM-related cerebral infarction [91]. Sesamol (3,4-methylenedioxyphenol) is a natural organic compound that is found in sesame seed. A previous study revealed that sesamol reduced oxidative stress, inflammation, acetylcholinesterase, and cognitive deficit in diabetic rats [92]. 8-O-acetyl shanzhiside methyl ester, an iridoid glucoside isolated from leaves of Lamiophlomis rotate kudo, reduced BBB damage in diabetic cerebral ischemia and reperfusion injury through downregulating HMGB1 and NF- $\kappa \mathrm{B}$ signaling pathway [93]. Furthermore, rosmarinic acid, commonly found in species of the Boraginaceae, was investigated in a cultured neuronal cell line and experimental ischemic stroke with diabetes. Rosmarinic acid attenuated the brain damage in diabatic stroke rat through HMGB1 and NF- $\mathrm{B}$ signaling pathway [94]. Moreover, Ecklonia cava polyphenols (ECP), having a strongly antioxidant properties, significantly reduced infarct volume and neuronal apoptosis 
in MCAO rat model [95]. In in vitro study, it blocked the rise in cytosolic calcium in differentiated SH-SY5Y cells exposed to $\mathrm{H}_{2} \mathrm{O}_{2}$ [95]. Previous study reported that this compound decreased glucogenesis through modulating of AMPK $\alpha$ pathway [96]. These findings suggest that ECP may have a therapeutic potential for the treatment of stroke, as well as diabetic stroke. There are several naturals products can reduce BBB damage in stroke with diabetic animals. However, there is limited evidence for clinical efficacy.

\section{Conclusion}

Ischemic stroke is a crucial cause of ischemic stroke. DM induces microvascular and macrovascular changes, and BBB breakdown that facilitates inflammatory events after stroke. BBB disruption has been considered the initial step that induce neurological deficit and functional disabilities. Functional outcomes in stroke are significantly worse among DM. Hyperglycemia is a serious problem in DM and is strongly related to high mortality and morbidity level in ischemic stroke patients that is caused by increased ROS production and future inflammation damaging BBB. Anti-oxidant, antiinflammatory properties may possibly the therapeutic targets for stroke with diabetes. Moreover, natural compounds may be alternative treatment for diabetic after stoke.

\section{ORCID}

Piyawadee Wicha: https://orcid.org/0000-0002-3048-4566

Srijit Das: https://orcid.org/0000-0001-8302-7257

Pasuk Mahakkanukrauh:

https://orcid.org/0000-0003-0611-7552

\section{Author Contributions}

Conceptualization: PM. Data acquisition: PW. Data analysis or interpretation: SD. Drafting of the manuscript: PW. Critical revision of the manuscript: SD, PM. Approval of the final version of the manuscript: all authors.

\section{Conflicts of Interest}

No potential conflict of interest relevant to this article was reported.

\section{Acknowledgements}

We would like to thank the Excellence in Osteology Research and Training Center (ORTC) with partially supported by Chiang Mai University.

\section{References}

1. Goldstein LB, Adams R, Becker K, Furberg CD, Gorelick PB, Hademenos G, Hill M, Howard G, Howard VJ, Jacobs B, Levine SR, Mosca L, Sacco RL, Sherman DG, Wolf PA, del Zoppo GJ. Primary prevention of ischemic stroke: a statement for healthcare professionals from the Stroke Council of the American Heart Association. Stroke 2001;32:280-99.

2. Capes SE, Hunt D, Malmberg K, Pathak P, Gerstein HC. Stress hyperglycemia and prognosis of stroke in nondiabetic and diabetic patients: a systematic overview. Stroke 2001;32:2426-32.

3. Mankovsky BN, Ziegler D. Stroke in patients with diabetes mellitus. Diabetes Metab Res Rev 2004;20:268-87.

4. Megherbi SE, Milan C, Minier D, Couvreur G, Osseby GV, Tilling K, Di Carlo A, Inzitari D, Wolfe CD, Moreau T, Giroud M; European BIOMED Study of Stroke Care Group. Association between diabetes and stroke subtype on survival and functional outcome 3 months after stroke: data from the European BIOMED Stroke Project. Stroke 2003;34:688-94.

5. Yong M, Kaste M. Dynamic of hyperglycemia as a predictor of stroke outcome in the ECASS-II trial. Stroke 2008;39:2749-55.

6. Hawkins BT, Lundeen TF, Norwood KM, Brooks HL, Egleton RD. Increased blood-brain barrier permeability and altered tight junctions in experimental diabetes in the rat: contribution of hyperglycaemia and matrix metalloproteinases. Diabetologia 2007;50:202-11.

7. Horani MH, Mooradian AD. Effect of diabetes on the blood brain barrier. Curr Pharm Des 2003;9:833-40.

8. Serlin Y, Levy J, Shalev H. Vascular pathology and blood-brain barrier disruption in cognitive and psychiatric complications of type 2 diabetes mellitus. Cardiovasc Psychiatry Neurol 2011;2011:609202.

9. Simpson IA, Appel NM, Hokari M, Oki J, Holman GD, Maher F, Koehler-Stec EM, Vannucci SJ, Smith QR. Blood-brain barrier glucose transporter: effects of hypo- and hyperglycemia revisited. J Neurochem 1999;72:238-47.

10. Abdullahi W, Tripathi D, Ronaldson PT. Blood-brain barrier dysfunction in ischemic stroke: targeting tight junctions and transporters for vascular protection. Am J Physiol Cell Physiol 2018;315:C343-56.

11. Abbott NJ, Patabendige AA, Dolman DE, Yusof SR, Begley DJ. Structure and function of the blood-brain barrier. Neurobiol Dis 2010;37:13-25.

12. Keaney J, Campbell M. The dynamic blood-brain barrier. FEBS J 2015;282:4067-79.

13. Li AC, Thompson RP. Basement membrane components. J Clin 
Pathol 2003;56:885-7.

14. Huber JD, Egleton RD, Davis TP. Molecular physiology and pathophysiology of tight junctions in the blood-brain barrier. Trends Neurosci 2001;24:719-25.

15. Obermeier B, Verma A, Ransohoff RM. The blood-brain barrier. Handb Clin Neurol 2016;133:39-59.

16. Piccio L, Rossi B, Scarpini E, Laudanna C, Giagulli C, Issekutz AC, Vestweber D, Butcher EC, Constantin G. Molecular mechanisms involved in lymphocyte recruitment in inflamed brain microvessels: critical roles for P-selectin glycoprotein ligand-1 and heterotrimeric G(i)-linked receptors. J Immunol 2002;168:1940-9.

17. Gee JR, Keller JN. Astrocytes: regulation of brain homeostasis via apolipoprotein E. Int J Biochem Cell Biol 2005;37:1145-50.

18. Armulik A, Genové G, Mäe M, Nisancioglu MH, Wallgard E, Niaudet C, He L, Norlin J, Lindblom P, Strittmatter K, Johansson BR, Betsholtz C. Pericytes regulate the blood-brain barrier. Nature 2010;468:557-61.

19. Daneman R, Zhou L, Kebede AA, Barres BA. Pericytes are required for blood-brain barrier integrity during embryogenesis. Nature 2010;468:562-6.

20. Daneman R, Prat A. The blood-brain barrier. Cold Spring Harb Perspect Biol 2015;7:a020412.

21. Nitta T, Hata M, Gotoh S, Seo Y, Sasaki H, Hashimoto N, Furuse $\mathrm{M}$, Tsukita $\mathrm{S}$. Size-selective loosening of the blood-brain barrier in claudin-5-deficient mice. J Cell Biol 2003;161:653-60.

22. Liebner S, Corada M, Bangsow T, Babbage J, Taddei A, Czupalla CJ, Reis M, Felici A, Wolburg H, Fruttiger M, Taketo MM, von Melchner H, Plate KH, Gerhardt H, Dejana E. Wnt/ beta-catenin signaling controls development of the blood-brain barrier. J Cell Biol 2008;183:409-17.

23. Saitou M, Furuse M, Sasaki H, Schulzke JD, Fromm M, Takano $\mathrm{H}$, Noda T, Tsukita S. Complex phenotype of mice lacking occludin, a component of tight junction strands. Mol Biol Cell 2000;11:4131-42.

24. Van Itallie CM, Anderson JM. Claudin interactions in and out of the tight junction. Tissue Barriers 2013;1:e25247.

25. Löscher W, Potschka H. Blood-brain barrier active efflux transporters: ATP-binding cassette gene family. NeuroRx 2005;2:86-98.

26. Erdő F, Krajcsi P. Age-related functional and expressional changes in efflux pathways at the blood-brain barrier. Front Aging Neurosci 2019;11:196.

27. Shah K, Desilva S, Abbruscato T. The role of glucose transporters in brain disease: diabetes and Alzheimer's disease. Int J Mol Sci 2012;13:12629-55.

28. Luchsinger JA, Tang MX, Stern Y, Shea S, Mayeux R. Diabetes mellitus and risk of Alzheimer's disease and dementia with stroke in a multiethnic cohort. Am J Epidemiol 2001;154:63541.

29. Prasad S, Sajja RK, Naik P, Cucullo L. Diabetes mellitus and blood-brain barrier dysfunction: an overview. J Pharmacovigil 2014;2:125.

30. Chen M, Zheng H, Xu M, Zhao L, Zhang Q, Song J, Zhao Z,
Lu S, Weng Q, Wu X, Yang W, Fan X, Gao H, Ji J. Changes in hepatic metabolic profile during the evolution of STZ-induced diabetic rats via an ${ }^{1} \mathrm{H}$ NMR-based metabonomic investigation. Biosci Rep 2019;39:BSR20181379.

31. Jurysta C, Nicaise C, Giroix MH, Cetik S, Malaisse WJ, Sener A. Comparison of GLUT1, GLUT2, GLUT4 and SGLT1 mRNA expression in the salivary glands and six other organs of control, streptozotocin-induced and Goto-Kakizaki diabetic rats. Cell Physiol Biochem 2013;31:37-43.

32. Younessi P, Yoonessi A. Advanced glycation end-products and their receptor-mediated roles: inflammation and oxidative stress. Iran J Med Sci 2011;36:154-66.

33. Stentz FB, Umpierrez GE, Cuervo R, Kitabchi AE. Proinflammatory cytokines, markers of cardiovascular risks, oxidative stress, and lipid peroxidation in patients with hyperglycemic crises. Diabetes 2004;53:2079-86.

34. Volpe CMO, Villar-Delfino PH, Dos Anjos PMF, NogueiraMachado JA. Cellular death, reactive oxygen species (ROS) and diabetic complications. Cell Death Dis 2018;9:119.

35. World Health Organization (WHO). The Global burden of disease: 2004 update. Geneva: World Health Organization; 2008.

36. Tun NN, Arunagirinathan G, Munshi SK, Pappachan JM. Diabetes mellitus and stroke: a clinical update. World J Diabetes 2017;8:235-48.

37. Fujimura M, Gasche Y, Morita-Fujimura Y, Massengale J, Kawase $\mathrm{M}$, Chan PH. Early appearance of activated matrix metalloproteinase- 9 and blood-brain barrier disruption in mice after focal cerebral ischemia and reperfusion. Brain Res 1999;842:92100.

38. Fukuda AM, Badaut J. Aquaporin 4: a player in cerebral edema and neuroinflammation. J Neuroinflammation 2012;9:279.

39. Candelario-Jalil E, Yang Y, Rosenberg GA. Diverse roles of matrix metalloproteinases and tissue inhibitors of metalloproteinases in neuroinflammation and cerebral ischemia. Neuroscience 2009;158:983-94.

40. Chodobski A, Zink BJ, Szmydynger-Chodobska J. Blood-brain barrier pathophysiology in traumatic brain injury. Transl Stroke Res 2011;2:492-516.

41. Uyttenboogaart M, Koch MW, Stewart RE, Vroomen PC, Luijckx GJ, De Keyser J. Moderate hyperglycaemia is associated with favourable outcome in acute lacunar stroke. Brain 2007;130(Pt 6):1626-30.

42. Ramasamy R, Yan SF, Schmidt AM. Receptor for AGE (RAGE): signaling mechanisms in the pathogenesis of diabetes and its complications. Ann N Y Acad Sci 2011;1243:88-102.

43. Song EC, Chu K, Jeong SW, Jung KH, Kim SH, Kim M, Yoon BW. Hyperglycemia exacerbates brain edema and perihematomal cell death after intracerebral hemorrhage. Stroke 2003;34:2215-20.

44. Bruno A, Levine SR, Frankel MR, Brott TG, Lin Y, Tilley BC, Lyden PD, Broderick JP, Kwiatkowski TG, Fineberg SE; NINDS rt-PA Stroke Study Group. Admission glucose level and clinical outcomes in the NINDS rt-PA Stroke Trial. Neurology 2002;59:669-74. 
45. Barreras A, Gurk-Turner C. Angiotensin II receptor blockers. Proc (Bayl Univ Med Cent) 2003;16:123-6.

46. O'Keefe JH, Wetzel M, Moe RR, Bronsnahan K, Lavie CJ. Should an angiotensin-converting enzyme inhibitor be standard therapy for patients with atherosclerotic disease? J Am Coll Cardiol 2001;37:1-8.

47. Schiffrin EL, Park JB, Intengan HD, Touyz RM. Correction of arterial structure and endothelial dysfunction in human essential hypertension by the angiotensin receptor antagonist losartan. Circulation 2000;101:1653-9.

48. Ido A, Hasebe N, Takeuchi T, Kikuchi K. Effects of temocapril and olmesartan on myocardial sympathetic nervous activity and fatty acid metabolism in rats with chronic beta-adrenergic stimulation. J Cardiovasc Pharmacol 2003;41 Suppl 1:S133-7.

49. Yamaguchi K, Ura N, Murakami H, Togashi N, Hyakukoku M, Higashiura K, Shimamoto K. Olmesartan ameliorates insulin sensitivity by modulating tumor necrosis factor-alpha and cyclic AMP in skeletal muscle. Hypertens Res 2005;28:773-8.

50. Matsumura T, Kinoshita H, Ishii N, Fukuda K, Motoshima H, Senokuchi T, Taketa K, Kawasaki S, Nishimaki-Mogami T, Kawada T, Nishikawa T, Araki E. Telmisartan exerts antiatherosclerotic effects by activating peroxisome proliferatoractivated receptor- $\gamma$ in macrophages. Arterioscler Thromb Vasc Biol 2011;31:1268-75.

51. Tan XY, Hu JB. ACEIs/ARBs for the prevention of type 2 diabetes in patients with cardiovascular diseases: a systematic review and meta-analysis. Int J Clin Exp Med 2016;9:7624-37.

52. Kuwashiro T, Kamouchi M, Ago T, Hata J, Sugimori H, Kitazono $\mathrm{T}$. The factors associated with a functional outcome after ischemic stroke in diabetic patients: the Fukuoka Stroke Registry. J Neurol Sci 2012;313:110-4.

53. Baird TA, Parsons MW, Phan T, Butcher KS, Desmond PM, Tress BM, Colman PG, Chambers BR, Davis SM. Persistent poststroke hyperglycemia is independently associated with infarct expansion and worse clinical outcome. Stroke 2003;34:2208-14.

54. Fuentes B, Castillo J, San José B, Leira R, Serena J, Vivancos J, Dávalos A, Nuñez AG, Egido J, Díez-Tejedor E; Stroke Project of the Cerebrovascular Diseases Study Group, Spanish Society of Neurology. The prognostic value of capillary glucose levels in acute stroke: the GLycemia in acute stroke (GLIAS) study. Stroke 2009;40:562-8.

55. Boussageon R, Bejan-Angoulvant T, Saadatian-Elahi M, Lafont S, Bergeonneau C, Kassaï B, Erpeldinger S, Wright JM, Gueyffier F, Cornu C. Effect of intensive glucose lowering treatment on all cause mortality, cardiovascular death, and microvascular events in type 2 diabetes: meta-analysis of randomised controlled trials. BMJ 2011;343:d4169.

56. Duckworth W, Abraira C, Moritz T, Reda D, Emanuele N, Reaven PD, Zieve FJ, Marks J, Davis SN, Hayward R, Warren SR, Goldman S, McCarren M, Vitek ME, Henderson WG, Huang GD. Glucose control and vascular complications in veterans with type 2 diabetes. N Engl J Med 2009;360:129-39.

57. Gerstein HC, Miller ME, Genuth S, Ismail-Beigi F, Buse JB,
Goff DC Jr, Probstfield JL, Cushman WC, Ginsberg HN, Bigger JT, Grimm RH Jr, Byington RP, Rosenberg YD, Friedewald WT. Long-term effects of intensive glucose lowering on cardiovascular outcomes. N Engl J Med 2011;364:818-28.

58. Hemmingsen B, Lund SS, Gluud C, Vaag A, Almdal TP, Hemmingsen C, Wetterslev J. Targeting intensive glycaemic control versus targeting conventional glycaemic control for type 2 diabetes mellitus. Cochrane Database Syst Rev 2013;(11):CD008143.

59. Patel A, MacMahon S, Chalmers J, Neal B, Billot L, Woodward M, Marre M, Cooper M, Glasziou P, Grobbee D, Hamet P, Harrap S, Heller S, Liu L, Mancia G, Mogensen CE, Pan C, Poulter N, Rodgers A, Williams B, Bompoint S, de Galan BE, Joshi R, Travert F. Intensive blood glucose control and vascular outcomes in patients with type 2 diabetes. N Engl J Med 2008;358:2560-72.

60. Bonnet F, Scheen AJ. Impact of glucose-lowering therapies on risk of stroke in type 2 diabetes. Diabetes Metab 2017;43:299313.

61. Castilla-Guerra L, Fernandez-Moreno MDC, Leon-Jimenez D, Carmona-Nimo E. Antidiabetic drugs and stroke risk. Current evidence. Eur J Intern Med 2018;48:1-5.

62. Lee JC, Won MH. Neuroprotection of antioxidant enzymes against transient global cerebral ischemia in gerbils. Anat Cell Biol 2014;47:149-56.

63. Li H, Luo Y, Yang P, Liu J. Hydrogen as a complementary therapy against ischemic stroke: a review of the evidence. J Neurol Sci 2019;396:240-6.

64. Shinohara Y, Saito I, Kobayashi S, Uchiyama S. Edaravone (radical scavenger) versus sodium ozagrel (antiplatelet agent) in acute noncardioembolic ischemic stroke (EDO trial). Cerebrovasc Dis 2009;27:485-92.

65. Hu Q, Manaenko A, Bian H, Guo Z, Huang JL, Guo ZN, Yang $\mathrm{P}$, Tang J, Zhang JH. Hyperbaric oxygen reduces infarction volume and hemorrhagic transformation through ATP/NAD+/ Sirtl pathway in hyperglycemic middle cerebral artery occlusion rats. Stroke 2017;48:1655-64.

66. Ning R, Venkat P, Chopp M, Zacharek A, Yan T, Cui X, Seyfried D, Chen J. D-4F increases microRNA-124a and reduces neuroinflammation in diabetic stroke rats. Oncotarget 2017;8:95481-94.

67. Iwasawa E, Ichijo M, Ishibashi S, Yokota T. Acute development of collateral circulation and therapeutic prospects in ischemic stroke. Neural Regen Res 2016;11:368-71.

68. Wang J, Hu W, Li L, Huang X, Liu Y, Wang D, Teng L. Antidiabetic activities of polysaccharides separated from Inonotus obliquus via the modulation of oxidative stress in mice with streptozotocin-induced diabetes. PLoS One 2017;12:e0180476.

69. Hong P, Gu RN, Li FX, Xiong XX, Liang WB, You ZJ, Zhang HF. NLRP3 inflammasome as a potential treatment in ischemic stroke concomitant with diabetes. J Neuroinflammation 2019;16:121.

70. Hu J, Liu B, Zhao Q, Jin P, Hua F, Zhang Z, Liu Y, Zan K, Cui $\mathrm{G}$, Ye X. Bone marrow stromal cells inhibits HMGB1-mediated 
inflammation after stroke in type 2 diabetic rats. Neuroscience 2016;324:11-9.

71. Xiang J, Hu J, Shen T, Liu B, Hua F, Zan K, Zu J, Cui G, Ye X. Bone marrow mesenchymal stem cells-conditioned medium enhances vascular remodeling after stroke in type 2 diabetic rats. Neurosci Lett 2017;644:62-6.

72. Venkat P, Yan T, Chopp M, Zacharek A, Ning R, Van Slyke P, Dumont D, Landschoot-Ward J, Liang L, Chen J. Angiopoietin-1 mimetic peptide promotes neuroprotection after stroke in type 1 diabetic rats. Cell Transplant 2018;27:1744-52.

73. Nakagawa S, Aruga J. Sphingosine 1-phosphate signaling is involved in impaired blood-brain barrier function in ischemiareperfusion injury. Mol Neurobiol 2020;57:1594-606.

74. Sanchez T. Sphingosine-1-phosphate signaling in endothelial disorders. Curr Atheroscler Rep 2016;18:31.

75. Li YJ, Shi SX, Liu Q, Shi FD, Gonzales RJ. Targeted role for sphingosine-1-phosphate receptor 1 in cerebrovascular integrity and inflammation during acute ischemic stroke. Neurosci Lett 2020;735:135160.

76. Kurano M, Tsukamoto K, Shimizu T, Kassai H, Nakao K, Aiba A, Hara M, Yatomi Y. Protection against insulin resistance by apolipoprotein M/sphingosine-1-phosphate. Diabetes 2020;69:867-81.

77. Li S, Wang N, Guo X, Li J, Zhang T, Ren G, Li D. Fibroblast growth factor 21 regulates glucose metabolism in part by reducing renal glucose reabsorption. Biomed Pharmacother 2018;108:355-66.

78. Tezze C, Romanello V, Sandri M. FGF21 as modulator of metabolism in health and disease. Front Physiol 2019;10:419.

79. Woo YC, Xu A, Wang Y, Lam KS. Fibroblast growth factor 21 as an emerging metabolic regulator: clinical perspectives. Clin Endocrinol (Oxf) 2013;78:489-96.

80. Wang D, Liu F, Zhu L, Lin P, Han F, Wang X, Tan X, Lin L, Xiong Y. FGF21 alleviates neuroinflammation following ischemic stroke by modulating the temporal and spatial dynamics of microglia/macrophages. J Neuroinflammation 2020;17:257.

81. Jiang Y, Lin L, Liu N, Wang Q, Yuan J, Li Y, Chung KK, Guo S, Yu Z, Wang X. FGF21 protects against aggravated blood-brain barrier disruption after ischemic focal stroke in diabetic $\mathrm{db} / \mathrm{db}$ male mice via cerebrovascular PPAR $\gamma$ activation. Int J Mol Sci 2020;21:824.

82. Zhong C, Yang J, Xu T, Xu T, Peng Y, Wang A, Wang J, Peng H, Li Q, Ju Z, Geng D, Zhang Y, He J. Serum matrix metalloproteinase-9 levels and prognosis of acute ischemic stroke. Neurology 2017;89:805-12.

83. Darsalia V, Hua S, Larsson M, Mallard C, Nathanson D, Nyström T, Sjöholm Å, Johansson ME, Patrone C. Exendin-4 reduces ischemic brain injury in normal and aged type 2 diabetic mice and promotes microglial M2 polarization. PLoS One 2014;9:e103114.
84. Chen $\mathrm{X}$, Jiang $\mathrm{H}$. Tau as a potential therapeutic target for ischemic stroke. Aging (Albany NY) 2019;11:12827-43.

85. Tuo QZ, Lei P, Jackman KA, Li XL, Xiong H, Li XL, Liuyang ZY, Roisman L, Zhang ST, Ayton S, Wang Q, Crouch PJ, Ganio K, Wang XC, Pei L, Adlard PA, Lu YM, Cappai R, Wang JZ, Liu R, Bush AI. Tau-mediated iron export prevents ferroptotic damage after ischemic stroke. Mol Psychiatry 2017;22:1520-30.

86. Bi M, Gladbach A, van Eersel J, Ittner A, Przybyla M, van Hummel A, Chua SW, van der Hoven J, Lee WS, Müller J, Parmar J, Jonquieres GV, Stefen H, Guccione E, Fath T, Housley GD, Klugmann M, Ke YD, Ittner LM. Tau exacerbates excitotoxic brain damage in an animal model of stroke. Nat Commun 2017;8:473.

87. Raz L, Bhaskar K, Weaver J, Marini S, Zhang Q, Thompson JF, Espinoza C, Iqbal S, Maphis NM, Weston L, Sillerud LO, Caprihan A, Pesko JC, Erhardt EB, Rosenberg GA. Hypoxia promotes tau hyperphosphorylation with associated neuropathology in vascular dysfunction. Neurobiol Dis 2019;126:12436.

88. Zhang T, Pan BS, Sun GC, Sun X, Sun FY. Diabetes synergistically exacerbates poststroke dementia and tau abnormality in brain. Neurochem Int 2010;56:955-61.

89. Hesse C, Rosengren L, Andreasen N, Davidsson P, Vanderstichele H, Vanmechelen E, Blennow K. Transient increase in total tau but not phospho-tau in human cerebrospinal fluid after acute stroke. Neurosci Lett 2001;297:187-90.

90. De Vos A, Bjerke M, Brouns R, De Roeck N, Jacobs D, Van den Abbeele L, Guldolf K, Zetterberg H, Blennow K, Engelborghs $S$, Vanmechelen E. Neurogranin and tau in cerebrospinal fluid and plasma of patients with acute ischemic stroke. BMC Neurol 2017;17:170.

91. Xia M, Ye Z, Shi Y, Zhou L, Hua Y. Curcumin improves diabetes mellitus-associated cerebral infarction by increasing the expression of GLUT1 and GLUT3. Mol Med Rep 2018;17:19639.

92. Kuhad A, Chopra K. Effect of sesamol on diabetes-associated cognitive decline in rats. Exp Brain Res 2008;185:411-20.

93. Zhang L, Kan ZC, Zhang XL, Fang H, Jiang WL. 8-O-acetyl shanzhiside methylester attenuates cerebral ischaemia/reperfusion injury through an anti-inflammatory mechanism in diabetic rats. Basic Clin Pharmacol Toxicol 2014;115:481-7.

94. Luan H, Kan Z, Xu Y, Lv C, Jiang W. Rosmarinic acid protects against experimental diabetes with cerebral ischemia: relation to inflammation response. J Neuroinflammation 2013;10:28.

95. Kim JH, Lee NS, Jeong YG, Lee JH, Kim EJ, Han SY. Protective efficacy of an Ecklonia cava extract used to treat transient focal ischemia of the rat brain. Anat Cell Biol 2012;45:103-13.

96. Yoon JY, Choi H, Jun HS. The effect of phloroglucinol, a component of Ecklonia cava extract, on hepatic glucose production. Mar Drugs 2017;15:106. 